\title{
Desenvolvimento de tambaqui submetido a períodos de privação alimentar
}

\author{
Daniel Rabello Ituassú(1), Gin Robson Santos dos Santos ${ }^{(1)}$, Rodrigo Roubach ${ }^{(1)}$ e Manoel Pereira-Filho ${ }^{(1)}$ \\ (1)Instituto Nacional de Pesquisas da Amazônia, Av. André Araújo, 2936, Aleixo, CEP 69060-001 Manaus, AM. E-mail: dituassu@inpa.gov.br, \\ ginrobson@yahoo.com.br, roubach@inpa.gov.br, pmanoel@inpa.gov.br
}

\begin{abstract}
Resumo - O objetivo deste trabalho foi avaliar o efeito da privação alimentar em parâmetros de crescimento e composição corporal de juvenis de tambaqui (Colossoma macropomum). Em um delineamento inteiramente casualizado, 180 juvenis pesando 75,68 $\pm 8,62 \mathrm{~g}$ foram distribuídos em 12 tanques de $180 \mathrm{~L}$ e submetidos a quatro períodos de privação $(0,14,21$ e 28 dias). A massa média dos peixes ao final do período de privação alimentar foi menor à medida que o tempo de privação aumentou. Ao final do experimento, somente peixes submetidos a 14 dias de privação alcançaram a massa dos peixes alimentados sem restrição. $O$ fator de condição não revelou diferenças significativas entre tratamentos ao final do período de privação ou ao final do experimento. As taxas de crescimento específico e o índice hepatossomático foram similares entre todos os tratamentos. Os peixes submetidos à privação exibiram os maiores valores de consumo diário de ração e os menores valores de eficiência alimentar. As porcentagens de umidade e proteína corporal foram maiores quanto maior o tempo de privação, mas não houve variações significativas dos níveis de extrato etéreo. Juvenis de tambaqui apresentam crescimento compensatório quando submetidos à privação alimentar.
\end{abstract}

Termos para indexação: Colossoma macropomum, nutrição de peixes, piscicultura, composição corporal.

\section{Growth of tambaqui submitted to different feed deprivation periods}

\begin{abstract}
The objective of this study was to evaluate the effect of feed deprivation on juvenile tambaqui (Colossoma macropomum) growth parameters and body composition. In a complete randomized design, one hundred and eighty fishes, weighting $75.68 \pm 8.62 \mathrm{~g}$ were maintained in twelve 180 - $\mathrm{L}$ tanks and submitted to four feed deprivation periods $(0,14,21$ and 28 days). Average fish weight at the end of feed deprivation period tended to be lower as deprivation period increased. At the end of the experiment only the fishes submitted to 14 days of feed deprivation attained similar weight to fish fed without restriction. Condition factor did not show any differences among treatments at the final of the deprivation period or at the end of the experiment. Specific growth rates and hepatosomatic index were similar among all treatments. Fish submitted to deprivation showed the highest daily feed consumption and lower feed efficiency values. Moisture and body protein contents were higher when feed deprivation increased but there was not a significant variation among ether extract levels. Tambaqui juveniles display compensatory growth when submitted to feed deprivation.
\end{abstract}

Index terms: Colossoma macropomum, fish nutrition, fish culture, body composition.

\section{Introdução}

O crescimento compensatório é uma das estratégias que podem ser empregadas no manejo alimentar de peixes para melhorar sua taxa de crescimento e, conseqüentemente, diminuir os custos de produção. Esta estratégia pode ser definida como um processo fisiológico no qual o organismo acelera o seu crescimento após um período de desenvolvimento restrito, normalmente em virtude da reduzida ingestão de alimento, de maneira a alcançar o peso dos animais que não sofreram privação alimentar (Hornick et al., 2000).
Em piscicultura o crescimento compensatório como estratégia de manejo alimentar está bem documentado em relação ao bagre-de-canal (Ictalurus punctatus) (Gaylord \& Gatlin III, 2000), salmonídeos (Jobling \& Koskela,1996; Nicieza \& Metcalfe, 1997), ciprinídeos (Bastrop et al., 1991) e outras espécies, como o "artic charr" (Salvelinus alpinus) (Miglavs \& Jobling, 1989) e o híbrido de "sunfish" (Lepomis macrochirus), por Hayward et al. (1997). Entretanto, informações sobre respostas de peixes tropicais à privação alimentar são escassas. 
Na Amazônia, uma das espécies atualmente mais cultivadas é o tambaqui, Colossoma macropomum, cujo cultivo na região iniciou-se no começo da década de 1980 (Rolim, 1995; Maeda, 1998). Esta espécie é uma das mais importantes para a economia regional, e sua oferta já chegou a representar quase a metade do total de pescado comercializado em Manaus (Araújo-Lima $\&$ Goulding, 1998). No entanto, o uso da teoria do crescimento compensatório como estratégia de manejo alimentar na criação do tambaqui ainda não foi objeto de investigação.

O objetivo deste trabalho foi avaliar o efeito da privação alimentar sobre parâmetros de crescimento e composição corporal de juvenis de tambaqui.

\section{Material e Métodos}

O experimento foi conduzido de novembro/2002 a fevereiro/2003 na Coordenação de Pesquisas em Aquacultura do INPA. Cento e oitenta juvenis de tambaqui adquiridos de uma piscicultura comercial local foram mantidos por um período de aclimatação de 14 dias em um tanque de $120 \mathrm{~m}^{2}$, durante o qual foram alimentados até a saciedade aparente, com uma ração comercial extrusada com $36 \%$ de proteína bruta. Em seguida, os peixes foram pesados $(75,68 \pm 8,62 \mathrm{~g})$ (média $\pm \mathrm{DP})$, e distribuídos homogeneamente $(\mathrm{p}=0,131)$ em 12 tanques de cimento amianto cobertos com tela sombrite, com um volume útil aproximado de $180 \mathrm{~L}$, abastecidos por água de poço artesiano a uma vazão de $0,5 \mathrm{~L} / \mathrm{min}$ e com regime natural de iluminação.

Em um delineamento inteiramente casualizado, os tanques foram sorteados entre quatro tratamentos: alimentação sem restrição (controle) e privação por 14, 21 e 28 dias. Os peixes do tratamento sem privação, e os peixes dos outros três tratamentos após os períodos de privação alimentar, foram alimentados diariamente às $9 \mathrm{~h}$ e às $15 \mathrm{~h}$ com uma ração comercial extrusada contendo $36 \%$ de proteína bruta, até o total de 98 dias de experimento.

A qualidade da água foi monitorada medindo-se diariamente a condutividade elétrica $\left(\mu \mathrm{S} / \mathrm{cm}^{2}\right), \mathrm{pH}$, temperatura $\left({ }^{\circ} \mathrm{C}\right)$ e oxigênio dissolvido $(\mathrm{mg} / \mathrm{L})$. As concentrações de amônia total $\left(\mathrm{NH}_{3}+\mathrm{NH}_{4}{ }^{+}\right)(\mathrm{mg} / \mathrm{L})$ foram semanalmente analisadas pelo método do salicilato (Verdow et al., 1978).

$\mathrm{Na}$ avaliação dos tratamentos, para acompanhamento do desempenho de crescimento dos peixes, foram feitas amostragens a cada duas semanas, até o final do experimento. $\mathrm{Na}$ avaliação da composição corporal dos peixes, foi sacrificado um exemplar de cada tanque (três por tratamento), para análise em triplicata dos teores de matéria seca, cinzas, lipídeos e proteína bruta das carcaças. As análises foram realizadas de acordo com as normas da Association of the Official Analytical Chemists (1995). Estas amostragens foram realizadas no início e no final do período experimental.

A cada unidade experimental, duas análises de regressão foram realizadas a partir dos dados das biometrias quinzenais. Em uma, o tempo em dias foi usado como variável independente e a massa média dos peixes como variável dependente, ao passo que na outra o tempo em dias foi usado como variável independente e o comprimento furcal como variável dependente. Os modelos gerados para cada unidade experimental foram usados para estimar as massas médias dos peixes e o fator de condição segundo a fórmula $\mathrm{K}=100 x\left[\right.$ massa $(\mathrm{g}) / \mathrm{comp}$. furcal $\left.(\mathrm{cm})^{3}\right]$ no $28^{\circ}$ e $98^{\circ}$ dia (final do período de privação e final do experimento, respectivamente).

Com os dados da última biometria (98 dias), calculou-se a taxa de crescimento específico, TCE $=100 x[\ln$ massa final $(\mathrm{g})$ - lnmassa inicial $(\mathrm{g})] /$ dias; eficiência alimentar, EA=100x [ganho de massa (g)/quantidade de ração ingerida $(\mathrm{g})]$; o consumo diário de ração, $\mathrm{CDR}=100 \times[$ (quantidade de ração $(\mathrm{g}) /$ biomassa de peixe $(\mathrm{g})) / \mathrm{dias}]$, e o índice hepatossomático, IHS $=100 x$ [massa do fígado $(\mathrm{g}) /$ massa do peixe $(\mathrm{g})]$.

As variáveis de desempenho e a composição corporal dos peixes foram submetidas à análise de variância $(\mathrm{p}<0,05)$, e aquelas que apresentaram diferenças significativas tiveram suas médias comparadas pelo teste de Tukey ( $p<0,05)$ (Zar, 1996). Os dados das análises centesimais (umidade, proteína bruta, cinzas e extrato etéreo), taxa de crescimento específico, eficiência alimentar, consumo diário de ração e IHS foram submetidos à transformação do arco seno antes das análises (Zar, 1996) e os dados de pH e amônia total foram transformados por $\ln (\mathrm{x})$ antes das análises.

As médias de oxigênio dissolvido foram comparadas pelo teste de Tukey $(\mathrm{p}<0,05)$. As análises dos dados foram feitas por meio do aplicativo estatístico Bioestat 2.0 (Ayres et al., 2000).

\section{Resultados e Discussão}

A qualidade da água durante o experimento exibiu significativas variações nos valores de oxigênio dissol- 
vido e condutividade elétrica (Tabela 1). Não houve variações significativas nas outras variáveis monitoradas. Os valores de oxigênio dissolvido aumentaram com o número de dias de privação, ao passo que os valores de condutividade apresentaram uma relação inversa ao aumento do período de privação.

Estas variações dos níveis de oxigênio e condutividade elétrica podem ser atribuídas ao período de privação pelo qual os peixes passaram, pois a suspensão da alimentação diminui a produção e liberação de matéria orgânica de origem fecal, bem como sobras de ração na água, levando à diminuição do consumo de oxigênio dissolvido e diminuição dos valores médios de condutividade elétrica para o período total.

Os peixes submetidos à privação por diferentes períodos apresentaram massa diferenciada quando comparados com o tratamento sem restrição no $28^{\circ}$ dia de experimento, sendo a perda de massa maior quanto maior foi o período de privação alimentar (Tabela 2). Ao final do experimento, as massas dos peixes foram diferenciadas, de modo que os peixes do tratamento sem privação e do tratamento de 14 dias de privação alcançaram maiores massas finais médias (Tabela 2). As taxas de crescimento específico (TCE), para os tratamentos submetidos à privação foram similares às do tratamento sem privação (Tabela 3). Entretanto, o consumo diário de ração (CDR) aumentou significativamente nos tratamentos submetidos à privação. Não houve melhoria na eficiência alimentar (EA) dos tratamentos submetidos à privação, quando comparados com o tratamento sem restrição (Tabela 3 ).

Ao contrário do obtido quanto ao bagre-de-canal, Ictalurus punctatus (Kim \& Lovell, 1995), truta-arcoíris, Oncorhynchus mykiss (Jobling \& Koskela, 1996) e o turbot, Scophthalmus maximus (Saether \& Jobling, 1999), as taxas de crescimento encontradas para o tambaqui não aumentaram com o número de dias de privação. Segundo Metcalfe \& Monaghan (2001), deficiências nutricionais originadas de longos períodos de privação em estágios iniciais de desenvolvimento podem comprometer a habilidade dos organismos de recuperar-se quando os níveis adequados de alimentação são restabelecidos.

Isto explicaria os resultados encontrados para as massas médias finais dos tambaquis submetidos a $21 \mathrm{e}$ 28 dias de privação alimentar. Sob esta perspectiva, a privação alimentar a partir de 21 dias provoca danos irrecuperáveis aos juvenis de tambaqui com massa em torno de 75 g. Entretanto, a resposta compensatória do tambaqui à privação ocorre, uma vez que ao final do experimento, os peixes submetidos a 14 dias de privação exibiram massa similares aos dos peixes alimentados sem privação.

Os peixes submetidos à privação tornaram-se hiperfágicos quando a alimentação foi restabelecida, o que é visível no consumo diário de ração. Resultados semelhantes foram encontrados na truta-arco-íris, O. mykiss (Jobling \& Koskela, 1996), e em "gibel carp", Carassius auratus gibelio (Qian et al., 2000). Demonstrações de hiperfagia parecem ser respostas comumente encontradas nesses casos (Jobling \& Koskela, 1996), de modo que sua ocorrência pode ser vista como evidência de crescimento compensatório do tambaqui.

A eficiência alimentar também pode aumentar durante o crescimento compensatório (Gaylord \& Gatlin III, 2001), porém o mesmo não aconteceu com o tambaqui. Segundo Kim \& Lovell (1995), que registraram para o bagre-de-canal, Ictalurus punctatus, conversões alimentares similares entre peixes submetidos à restrição e peixes alimentados normalmente, as taxas de assimilação permaneceram as mesmas, provavelmente por causa da grande quantidade de alimento disponível aos peixes após o período de privação. Embora o consumo diário de ração tenha

Tabela 1. Oxigênio dissolvido (OD), temperatura, $\mathrm{pH}$, condutividade elétrica e amônia total $\left(\mathrm{NH}_{3}+\mathrm{NH}_{4}{ }^{+}\right)$nos tanques de juvenis de tambaqui, C. macropomum, alimentados sem restrição e submetidos a 14, 21 e 28 dias de privação alimentar $^{(1)}$.

\begin{tabular}{llclcc}
\hline Tratamento & OD $(\mathrm{mg} / \mathrm{L})$ & $\begin{array}{c}\text { Temperatura } \\
\left({ }^{\circ} \mathrm{C}\right)\end{array}$ & $\mathrm{pH}$ & $\begin{array}{c}\text { Condutividade } \\
\left(\mu \mathrm{S} / \mathrm{cm}^{2}\right)\end{array}$ & $\begin{array}{c}\mathrm{NH}_{3}+\mathrm{NH}_{4}^{+} \\
(\mathrm{mg} / \mathrm{L})\end{array}$ \\
\hline Sem restrição & $4,00 \pm 0,14 \mathrm{a}$ & $27,14 \pm 0,24$ & $5,74 \pm 0,16$ & $49,16 \pm 6,65 \mathrm{~b}$ & $0,64 \pm 0,20$ \\
14 dias & $4,86 \pm 0,11 \mathrm{ab}$ & $27,42 \pm 0,07$ & $5,68 \pm 0,01$ & $39,06 \pm 1,21 \mathrm{ab}$ & $0,57 \pm 0,04$ \\
21 dias & $4,77 \pm 0,04 \mathrm{ab}$ & $27,32 \pm 0,05$ & $5,55 \pm 0,09$ & $32,20 \pm 5,14 \mathrm{a}$ & $0,38 \pm 0,09$ \\
28 dias & $5,48 \pm 0,86 \mathrm{~b}$ & $27,39 \pm 0,08$ & $5,90 \pm 0,10$ & $31,64 \pm 5,89 \mathrm{a}$ & $0,36 \pm 0,12$ \\
\hline
\end{tabular}

${ }^{(1)}$ Médiası̇desvio-padrão seguidas de letras diferentes na mesma coluna indicam diferenças significativas a $5 \%$ de probabilidade pelo teste de Tukey; os dados de $\mathrm{pH}$ e amônia total foram transformados em $\ln (\mathrm{x})$ antes da análise. 
acompanhado o crescimento dos peixes, esta variável isolada não pode explicar as taxas de crescimento encontradas, devendo-se considerar os fatores fisiológicos presentes (Saether \& Jobling, 1996).

A exemplo do registrado quanto ao bagre-de-canal, (Kim \& Lovell, 1995), o fator de condição K não foi diferenciado entre os tratamentos nem no 28 o nem ao final do experimento (Tabela 2). O índice hepatossomático, ao final do experimento, revelou valores similares entre tratamentos (Tabela 3 ). $\mathrm{O}$ fato de registrarem-se $\mathrm{K}$ similares entre os diferentes períodos de privação e o período sem restrição revela que, embora nem todos os tratamentos tenham alcançado tamanhos finais similares, isto não significa que os peixes menores sejam obrigatoriamente peixes magros.

As análises corporais dos peixes não revelaram influência da privação alimentar sobre os porcentuais de cinzas e extrato etéreo. Esta influência ficou evidente nas porcentagens de umidade e proteína bruta, cujos valores aumentaram com o aumento dos dias de privação (Tabela 4).

Tabela 2. Massa média e fator de condição dos juvenis de tambaqui aos 28 e 98 dias, alimentados sem restrição e submetidos a 14, 21 e 28 dias de privação alimentar ${ }^{(1)}$.

\begin{tabular}{lccccc}
\hline Tratamento & \multicolumn{2}{c}{ Massa média $(\mathrm{g})$} & & \multicolumn{2}{c}{ Fator de condição } \\
\cline { 2 - 3 } \cline { 5 - 6 } & 28 & 98 & & 28 & 98 \\
\hline Sem restrição & $132,06 \pm 11,40 \mathrm{~b}$ & $197,50 \pm 17,18 \mathrm{~b}$ & & $2,73 \pm 0,10$ & $2,76 \pm 0,25$ \\
14 dias & $105,85 \pm 1,66 \mathrm{~b}$ & $225,20 \pm 22,92 \mathrm{~b}$ & & $2,60 \pm 0,10$ & $2,70 \pm 0,26$ \\
21 dias & $77,77 \pm 5,67 \mathrm{a}$ & $147,62 \pm 21,53 \mathrm{a}$ & & $2,33 \pm 0,12$ & $2,50 \pm 0,20$ \\
28 dias & $70,29 \pm 6,85 \mathrm{a}$ & $159,64 \pm 8,48 \mathrm{a}$ & & $2,40 \pm 0,24$ & $2,60 \pm 0,26$ \\
\hline
\end{tabular}

${ }^{(1)}$ Médias \pm desvio-padrão seguidas de letras diferentes na mesma coluna indicam diferenças significativas a $5 \%$ de probabilidade pelo teste de Tukey.

Tabela 3. Taxa de crescimento específico (TCE), eficiência alimentar (EA), consumo diário de ração (CDR) e índice hepatossomático (IHS) de juvenis de tambaqui, C. macropomum, alimentados sem restrição e submetidos à privação alimentar durante 14,21 e 28 dias $^{(1)}$.

\begin{tabular}{lcccc}
\hline Tratamento & TCE (\%/dia) & EA (\%) & CDR (\%) & IHS \\
\hline Sem restrição & $0,90 \pm 0,11$ & $63,89 \pm 6,40 \mathrm{~b}$ & $0,67 \pm 0,06 \mathrm{a}$ & $1,6 \pm 0,13$ \\
14 dias & $0,97 \pm 0,12$ & $31,56 \pm 11,3 \mathrm{a}$ & $1,00 \pm 0,10 \mathrm{~b}$ & $2,2 \pm 0,27$ \\
21 dias & $0,83 \pm 0,21$ & $43,14 \pm 3,19 \mathrm{a}$ & $0,97 \pm 0,15 \mathrm{~b}$ & $1,9 \pm 0,19$ \\
28 dias & $0,85 \pm 0,16$ & $43,74 \pm 8,92 \mathrm{a}$ & $1,07 \pm 0,06 \mathrm{~b}$ & $1,9 \pm 0,27$ \\
\hline (1) Médias \pm desvio-padrão seguidas de letras diferentes na mesma coluna \\
indicam diferenças significativas a 5\% de probabilidade pelo teste de \\
Tukey; os dados de TCE, EA, CDR e IHS foram submetidos à transfor- \\
mação do arco seno antes das análises.
\end{tabular}

Pesq. agropec. bras., Brasília, v.39, n.12, p.1199-1203, dez. 2004
Tabela 4. Análise corporal de tambaqui, C. macropomum, alimentados sem restrição e submetidos à privação alimentar de 14,21 e $28 \operatorname{dias}^{(1)}$.

\begin{tabular}{lcccc}
\hline Tratamento & \multicolumn{3}{c}{ Amostras a 100\% de matéria seca } \\
\cline { 2 - 5 } & Umidade & Cinzas & $\begin{array}{c}\text { Extrato } \\
\text { etéreo }\end{array}$ & $\begin{array}{c}\text { Proteína } \\
\text { bruta }\end{array}$ \\
\hline Sem restrição & $73,47 \pm 0,06 \mathrm{a}$ & $11,93 \pm 0,29$ & $23,37 \pm 0,40$ & $55,50 \pm 0,35 \mathrm{a}$ \\
14 dias & $76,10 \pm 0,00 \mathrm{ab}$ & $14,57 \pm 0,50$ & $23,30 \pm 0,36$ & $56,07 \pm 0,40 \mathrm{ab}$ \\
21 dias & $77,20 \pm 0,17 \mathrm{bc}$ & $13,87 \pm 0,76$ & $23,00 \pm 0,17$ & $58,73 \pm 0,23 \mathrm{c}$ \\
28 dias & $77,53 \pm 0,15 \mathrm{c}$ & $13,30 \pm 0,17$ & $19,57 \pm 0,25$ & $57,93 \pm 0,40 \mathrm{bc}$ \\
\hline
\end{tabular}

${ }^{(1)}$ Médias \pm desvio-padrão seguidas de letras diferentes na mesma coluna indicam diferenças significativas a $5 \%$ de probabilidade pelo teste de Tukey; os dados de umidade, cinzas e extrato etéreo foram submetidos à transformação do arco seno antes das análises.

Como registrado em relação ao bagre-de-canal (Kim \& Lovell, 1995), o conteúdo de extrato etéreo foi similar entre os tratamentos. O aumento porcentual de proteína bruta nos peixes que passaram por privação alimentar sugere um aumento da deposição de músculo, o que dá suporte à afirmação de que o aumento de massa como resposta à privação não é causado apenas pela deposição de gordura corporal (Dobson \& Holmes, 1984).

\section{Conclusões}

1. O tambaqui exibe crescimento compensatório quando submetido à privação alimentar.

2. A compensação do crescimento é total quando os peixes são submetidos à privação alimentar até 14 dias.

3. O tambaqui apresenta maior deposição de proteína corporal quando passa a ser alimentado à vontade após ser submetido à privação alimentar.

\section{Referências}

ARAÚJO-LIMA, C.A.R.M.; GOULDING, M. Os frutos do tambaqui: ecologia, conservação e cultivo na Amazônia. Tefé: Sociedade Civil Mamirauá; Brasília: CNPq, 1998. 186p.

ASSOCIATION Of THE OFFICIAL ANALYTICAL CHEMISTS (Arlington, Estados Unidos). Official methods of analysis. 16th ed. Arlington, 1995. 1117p.

AYRES, M.; AYRES JUNIOR, M.; AYRES, D.L.; SANTOS, A.S.D. Bioestat 2.0: aplicações estatísticas nas áreas das ciências biológicas e médicas. Belém: Sociedade Civil Mamirauá; Brasília: CNPq, 2000. $272 p$.

BASTROP, R.; SPANGENBERG, R.; JÜRSS, K. Biochemical adaptation of juvenile carp (Cyprinus carpio L.) to food deprivation. Comparative Biochemistry and Physiology - Part A: Molecular \& Integrative Physiology, v.98, p.143-149, 1991. 
DOBSON, S.H.; HOLMES, R.M. Compensatory growth in the rainbow trout, Salmo gairdneri Richardson. Journal of Fish Biology, v.25, p.649-656, 1984.

GAYLORD, T.G.; GATLIN III, D.M. Assessment of compensatory growth in channel catfish Ictalurus punctatus R. and associated changes in body condition indices. Journal of The World Aquaculture Society, v.31, p.326-336, 2000.

GAYLORD, T.G.; GATLIN III, D.M. Dietary protein and energy modifications to maximize compensatory growth of channel catfish (Ictalurus punctatus). Aquaculture, v.194, p.337-348, 2001.

HAYWARD, R.S.; NOLTIE, D.B.; WANG, N. Use of compensatory growth to double hybrid sunfish growth rates. Transactions of American Fisheries Society, v.126, p.316-322, 1997.

HORNICK, J.L.; VAN EENAEME, C.; GÉRARD, O.; DUFRASNE, I.; ISTASSE, L. Mechanisms of reduced and compensatory growth. Domestic Animal Endocrinology, v.19, p.121-132, 2000.

JOBLING, M.; KOSKELA, J. Interindividual variations in feeding and growth in rainbow trout during restricted feeding and in a subsequent period of compensatory growth. Journal of Fish Biology, v.49, p.658-667, 1996.

KIM, M.K.; LOVELL, R.T. Effect of restricted feeding regimens on compensatory weight gain and body tissue changes in channel catfish Ictalurus punctatus in ponds. Aquaculture, v.135, p.285-293, 1995.

MAEDA, L.S. Diagnóstico da piscicultura na região de produção em torno de Manaus. 1998. Monografia (graduação) - Universidade do Amazonas, Manaus.
METCALFE, N.B.; MONAGHAN, P. Compensation for bad start: grow now, pay later? Trends in Ecology \& Evolution, v.16, p.254260, 2001.

MIGLAVS, I.; JOBLING, M. Effects of feeding regime on foodconsumption, growth-rates and tissue nucleic-acids in juvenile arctic charr, Salvelinus alpinus, with particular respect to compensatory growth. Journal of Fish Biology, v.34, p.947-957, 1989.

NICIEZA, A.G.; METCALFE, N.B. Growth compensation in juvenile Atlantic salmon: Responses to depressed temperature and food availability. Ecology, v.78, p.2385-2400, 1997.

QIAN, X.; CUI, Y.; XIONG, B.; YANG, Y. Compensatory growth, feed utilization and activity in gibel carp, following feed deprivation. Journal of Fish Biology, v.56, p.228-232, 2000.

ROLIM, P.R. A infra-estrutura básica para a criação de peixes no Amazonas. In: VAL, A.L.; HONCZARYK, A. (Ed.). Criando peixes na Amazônia. Manaus: Instituto Nacional de Pesquisas da Amazônia, 1995. p.7-16.

SAETHER, B.S.; JOBLING, M. The effects of ration level on feed intake and growth, and compensatory growth after restricted feeding, in turbot Scophthalmus maximus L. Aquaculture Research, v.30, p.647-653, 1999.

VERDOW, H.; VAN ECTHTELD, C.J.A.; DEKKERS, E.M.J. Ammonia determination based on indophenol formation whit sodium salicylate. Water Research, v.12, p.399-402, 1978.

ZAR, J.H. Biostatistical analysis. Upper Saddle River: Prentice Hall, 1996. 699p. 